\title{
World at work: Cleaners
}

\section{J P Zock}

\section{Multiple occupational hazards in a large service sector}

$\mathrm{P}$ ofessional cleaning is a basic service occupation that is carried out worldwide in many different environments, both indoors and outdoors. Cleaning workers form an important proportion of the total working population; for instance 3\% in the USA, $4 \%$ in Finland, ${ }^{1}$ and $10 \%$ of the female working population in Spain. ${ }^{2}$ Cleaners often have low occupational skills and belong to the less advantaged educational and socioeconomic groups. ${ }^{3}$ There are a number of important differences in the organisation of cleaning jobs between geographical areas and their prevailing cultures, which are related to differences in work conditions and hence occupational hazards. In many countries cleaning work is predominantly done by women, with a relatively high proportion of older women. ${ }^{4}$ Immigrants constitute another major group doing cleaning work in many industrialised areas. Cleaners may be employed by private cleaning companies and sent out to clean buildings of various contractors, which may result in dispersed workplaces. An important number of cleaners are employed in the informal sector, particularly those in cleaning private homes, ${ }^{2}$ but also in cleaning bars, schools, and other places. This is often characterised by precarious employment, often part-time. The related low social and legal protection results in payment on an hourly basis without proper contracts or insurance. Taking into account all these particular characteristics, cleaners are likely to escape from control such as regulations, health surveillance, and risk prevention. The purpose of this paper is to provide a concise overview of the most common occupational hazards in cleaning work, and to discuss possibilities to improve control and prevention.

\section{TASKS OF THE JOB}

The main goals of cleaning are to maintain functionality, appearance, and appropriate hygienic conditions of buildings and public places outdoors. This may result in a wide variety of work tasks of the cleaning job. In many settings cleaners not only perform strictly "cleaning", but also other (related) activities such as disposing waste or wastewater. In addition, for some specific jobs such as domestic service work, many different tasks form part of the "cleaning" job, such as shopping, cooking, and child care. ${ }^{5}$

In general the main activity of the cleaning job is cleaning surfaces, particularly floors, furniture, sanitary fittings, windows, vehicles, machines, and other work equipment. This can be done by dusting, wiping, sweeping, or vacuuming, but is very often done with the aid of cleaning products. The use of these agents is common in most types of cleaning, and has four different, often supplemental purposes. Obviously the main goal of using cleaning products is to facilitate the removal of surface contaminants. This is based on physical and chemical processes, including the dissolution of deposits of minerals, fat, or inorganic salts by acid-base reactions, or by the forming of complexes ("micelles"). A second purpose is surface care; maintenance of the material and/or to make it appear more shiny. Thirdly, certain products aim at the disinfection of the surface. Finally, cleaning products may be used to introduce a pleasant smell, and perhaps even to mask an unpleasant smell. Depending on these purposes, and on the type of surface to be cleaned, products contain a wide variety of chemical components. ${ }^{67}$

\section{HAZARDS OF THE JOB AND IN THE WORKPLACE}

Occupational hazards in cleaning work may depend on the working tasks and cleaning equipment applied, on the

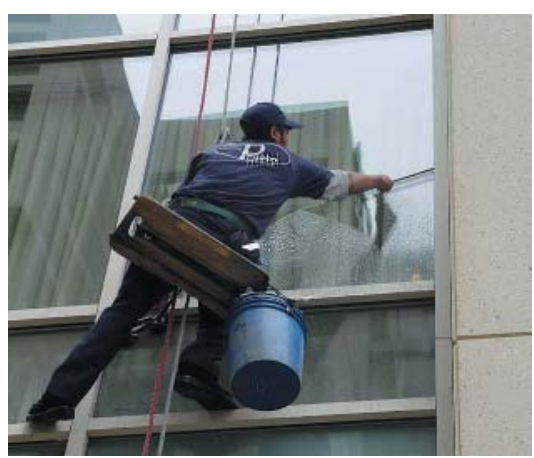

Figure 1 Window cleaner outdoors. cleaning products used, and on the environment to be cleaned. Regarding the latter, exposures are often inherent to the type of environment where the cleaning is performed and hence risks are related to the function of the cleaning location. A Finnish study suggested that the risk of asthma was highest for cleaners of industrial sites with a recognised risk of occupational asthma. ${ }^{8}$ Thus, exposures to products or waste from the manufacturing process where the cleaning is performed may be relevant.

Cleaners have unfavourable working hours; they often clean after or before regular working hours. In many offices and factories, mechanical ventilation, heating, and air conditioning are frequently turned off or are functioning at lower level during these hours. Consequently, cleaners are often exposed to cold, heat, and poor ventilation, and in the case of surgery rooms, laboratories, or workshops this may result in increased respiratory exposures.

Workplace exposure to cleaning products is ubiquitous and occurs in both industrial and non-industrial settings. It is not unusual for these products to be used in higher concentrations or larger amounts than necessary. This may be related to the deep rooted though unfounded belief that cleaning is done better and/or quicker this way. Mainly physical, safety, chemical, and psychosocial hazards can be distinguished in cleaning work.

\section{Physical workload and strain} Cleaning involves both dynamic and static muscular work done with the use of various pieces of manual equipment. Cleaning work is generally labour intensive and involves high cardiorespiratory and musculoskeletal loads. Physical hazards depend on current design of buildings, facilities, and furniture, as well as cleaning tools, machines, and methods. ${ }^{3}$ A large proportion of the work time is spent using long handled equipment (for example, sweeping, mopping). The static postural load is high; cleaners often work bent forward and/or with a twisted back. Repetitive muscular work of the arms in association with a high dynamic and static output of force is common. Frequently objects need to be moved in order to reach spaces to be cleaned. Disposing of heavy and/or bulky items that are put in rubbish bins can also be an important physical risk factor. Musculoskeletal disorders may include lower back pain, and symptoms affecting the neck, upper back, hips, shoulder, hand/wrist, and legs/feet; older women can be regarded as a risk group. 


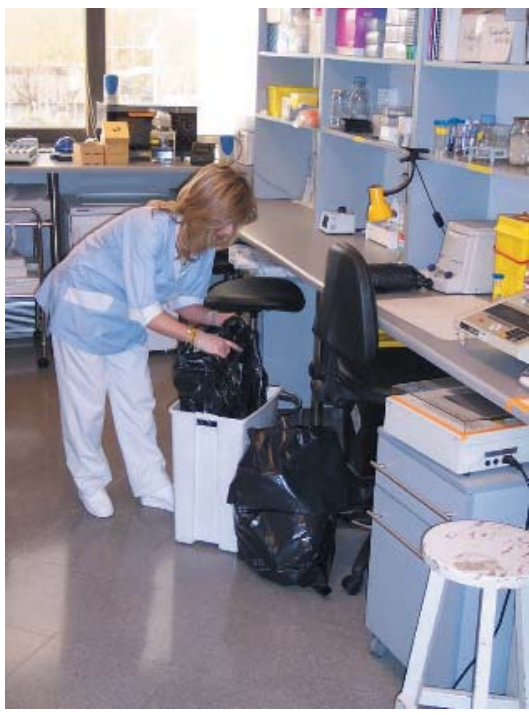

Figure 2 Waste disposal in a biomedical laboratory.

\section{Occupational accidents}

There is a general lack of safety regulations for cleaning work. An important factor is that buildings are typically designed for purposes other than cleaning. There is a common risk with stepladders or other means to reach and clean higher objects. At high risk for occupational injuries due to falls are window cleaners and others working at heights. Wet floors can cause slips. Street cleaners are at risk of road accidents. Other types of accidents include hospital needle prick incidents due to improperly stored waste, leading to infections such as hepatitis B. Inhalation accidents due to spills or inadequate mixtures will be described under chemical hazards.

\section{Chemical hazards}

Cleaning products typically contain many different chemical agents. The most important are listed in table 1. Many agents are corrosive at high concentrations, and irritant at lower concentrations. They may produce irritation of skin, eyes, and mucous membranes of upper and lower airways; and even skin burns related to intensive and/ or prolonged contact with high concentrations. Some components have sensitising properties. ${ }^{6}$

Both inhalatory and dermal exposures are relevant for cleaning workers. Respiratory exposure may occur due to evaporation of volatile components, which may be enhanced when applied on large surfaces such as floors. The use of products in spray form (including atomisers) facilitates inhalation of wet aerosols containing both volatile and non-volatile agents. Toxicological evaluation shows that the main effects occur on the skin and the respiratory tract.

\section{Dermal effects}

Skin contact principally affects the hands; hence this is where dermal effects are mainly seen. Cleaning agents contain substances that degrease and break down the natural barriers of the skin. Exposure to water (wet work) changes the defence mechanisms of the skin barrier, and the skin is then easier to penetrate and more sensitive to other chemical substances. Probably the most common disorder is (irritant) contact dermatitis, ${ }^{9}$ with symptoms such as itching, redness, rough skin, and vesicles on hands and (between) fingers. ${ }^{9}{ }^{10}$ Gloves protect the skin from wet work, and contact with chemical agents. Some cleaning agents may act as contact allergens. ${ }^{710} 11$ The use of disposable natural rubber latex gloves can be a risk factor for latex allergy of the skin.

\section{Respiratory effects}

Several cleaning agents cause mucosal membrane irritation leading to several respiratory symptoms including rhinitis, ${ }^{12}$ cough, and shortness of breath. ${ }^{13}$ Epidemiological studies have shown that cleaners are at increased risk of asthma, chronic bronchitis, and other respiratory symptoms. ${ }^{2} 814$ Atopy does not seem to play an important role in these associations. ${ }^{15}$ It is, however, largely unclear which specific exposures are associated with this risk. A Spanish study suggested that the risk was predominantly related to domestic cleaning, ${ }^{2}$ in particular to frequent use of bleach and other irritant agents. ${ }^{16}$ Cases of occupational asthma have been described in relation to airways sensitisers from cleaning agents. ${ }^{17}$

Inhalation accidents mainly occur after inadequate mixtures of incompatible cleaning products. ${ }^{18}$ The most commonly reported are bleach (active compound sodium hypochlorite) with acids (for example, phosphoric acid from toilet bowl cleaner; hydrochloric acid from decalcifiers), leading to a release of free chlorine. ${ }^{19}$ Mixing bleach with ammonia leads to the release of chloramines. $^{20}$ Inhalation of large amounts of chlorine or chloramines may lead to severe acute respiratory effects, including chronic conditions such as adult respiratory distress syndrome (ARDS), reactive airways dysfunction syndrome (RADS), or toxic/ chemical pneumonitis. ${ }^{21} 22$

\section{Other effects}

Some chemical components of cleaning agents have carcinogenic or neurotoxic properties, may act as endocrine dis- ruptors, or affect reproduction. Apart from adverse health effects in humans, environmental risks should be considered since certain cleaning chemicals can be toxic for other species and ecosystems.

\section{Psychosocial hazards}

Psychosocial risks may be related to a complex variety of factors in occupational cleaning. In certain locations, cleaners typically work alone. In connection with the fact that many clean after or before regular working hours, fear and risk of harassment and violence is not uncommon, particularly among women. In addition, also related to their working hours, cleaners are often excluded from social contacts such as coffee breaks. Many cleaners work in the informal sector, associated with precarious employment and low social and legal protection. ${ }^{23}$ Cleaning work is often perceived as a low status occupation. In general, cleaners have little or no chance to influence their work or to advance in their professional career (or even obtain any advantages from their work). There is little or no possibility to influence their work arrangements, work place, tools or machines, the division of labour, or choice of work partner. Work related stress and lack of control over work conditions is common. Other factors include physical strain, fatigue, time pressure, insufficient training, and monotonous work. Exposure to dirt and smells may cause psychosocial discomfort.

\section{Other hazards}

Apart from agents derived from cleaning products, biological exposures related to the building or the work environment may be relevant. Cleaning staff can be exposed to micro-organisms in dust or in aerosols released from waste during the cleaning process. Such exposure is also possible in connection with vacuuming processes when a large part of the dust can pass through the vacuuming cleaner. Biological dust can contain indoor allergens, moulds and fungal secretion products, and bacterial endotoxin, among others. Street and other outdoor cleaners are often exposed to combustion particles and fumes from vehicle exhaust.

\section{MEASURES TO PROTECT WORKERS}

Measures to control the different types of hazards described can be developed, suggested, and implemented at different levels. Since changes in the working environment are often not feasible, the following point-by-point options for control focus on administrative measures, education and other information, 
Table 1 Main chemical components of cleaning products

\begin{tabular}{|c|c|c|c|}
\hline Type of agent & Purpose & Examples & Potential health effects \\
\hline Detergents (surfactants) & Lower surface tension of water & $\begin{array}{l}\text { Fatty acid salts (soap), organic } \\
\text { sulphonates }\end{array}$ & Skin, eyes, and mucous membrane irritation \\
\hline $\begin{array}{l}\text { Complexing agents (water } \\
\text { softeners) }\end{array}$ & $\begin{array}{l}\text { Dissolve and bind calcium and other } \\
\text { cations; regulate the } \mathrm{pH}\end{array}$ & EDTA*, tripolyphosphates & Skin, eyes, and mucous membrane irritation \\
\hline Alkaline agents & $\begin{array}{l}\text { Dissolve fatty substances, disinfection, } \\
\text { inhibit corrosion of metal surfaces }\end{array}$ & $\begin{array}{l}\text { Silicates, carbonates, sodium } \\
\text { hydroxide, ammonia }\end{array}$ & Skin, eyes, and mucous membrane irritation \\
\hline Acids & Dissolve calcium & $\begin{array}{l}\text { Phosphoric, acetic, citric, sulphamic, } \\
\text { hydrochloric acid }\end{array}$ & Skin, eyes, and mucous membrane irritation \\
\hline Solvents & Dissolve fatty substances & Álcohols, glycol ethers & Neurotoxic \\
\hline Corrosion inhibitor & Protection of metal surfaces & Ethanol amines & Sensitisation \\
\hline Film formers, polishes & Surface care & Wax, acryl polymers, polyethylene & Sensitisation \\
\hline Disinfectants & Destroy bacteria and other micro-organisms & $\begin{array}{l}\text { Hypochlorite, aldehydes, quaternary } \\
\text { ammonium compounds }\end{array}$ & Sensitisation, mucous membrane irritation \\
\hline Preservatives & $\begin{array}{l}\text { Avoid microbial growth during product } \\
\text { storage }\end{array}$ & $\begin{array}{l}\text { Benzalkonium chloride, } \\
\text { isothiazolinones, formaldehyde }\end{array}$ & Sensitisation \\
\hline Perfumes, scents & Introduce pleasant smell & d-limonene, terpenes (pinene) & Sensitisation, irritation \\
\hline
\end{tabular}

good housekeeping, reduction of hazardous chemicals, avoidance of exposure, and personal protection.

- Administrative measures may include rotation of cleaning jobs, in order to reduce (distribute better) monotonous work, unfavourable working hours, or activities with high physical workload or environmental exposures.

- A training programme including written information (fact sheets) ${ }^{24}$ and education (person-to-person training or videos within courses or workshops) improves awareness of hazards and knowledge of simple ways to reduce risks. Technical information may include how to store, mix, and use products; how to avoid incompatibilities with other products; accessibility to the supplier's customer service system; and how to properly dispose of unused products, waste, and containers.

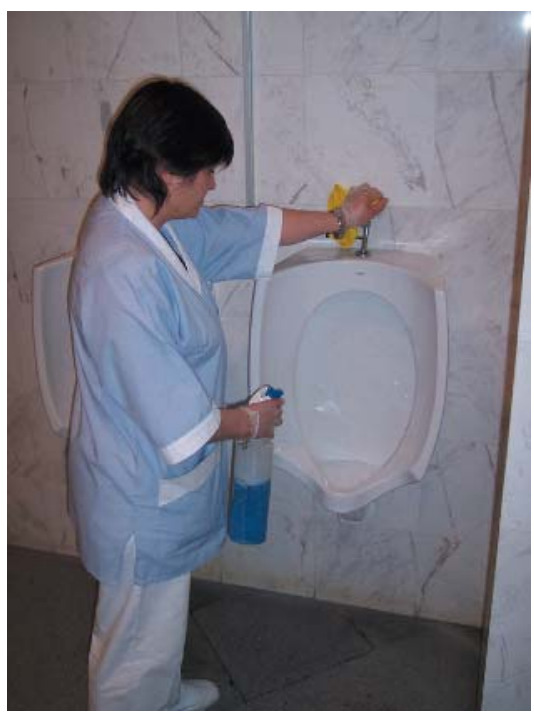

Figure 3 Sanitary cleaning.
- In certain situations tools can be replaced by long handled equipment to avoid bending postures.

- Cleaning equipment should be maintained well; routine checking, repair, and replacement should be done regularly.

- The use of carts to move cleaning tools and products from one place to another reduces musculoskeletal load

- Stable stepladders should always be used instead of chairs or other furniture to reach higher objects. Climbing the stepladder should be done wearing proper shoes with antislip soles, and never with both hands occupied.

- Waste bags should be handled using gloves, and bags must never be compressed.

- As a preventive measure, hospital cleaners should be vaccinated against hepatitis B.

- Before the application of cleaning products, the following should be considered: $:^{25}$

- Is it really necessary to use this strong/irritant product (ammonia, bleach, strong acids, degreasing sprays) or could it be replaced by other, less aggressive products?

- If necessary, could it be used less frequently, and/or in smaller quantities?

- Could it be used in another application form? (glass cleaning sprays can often without inconvenience be replaced by glass cleaning liquids, and inhalatory exposure consequently reduced.)

- In order to avoid dermal effects on the hands, the use of gloves can be recommended when working with cleaning products. In addition, direct skin contact with cleaning products should be avoided; wet hands should be minimised, and if wet, dried thoroughly. Finally, an appropriate hand cream should be applied after work.

- The mixing of cleaning products should always be avoided; even liquid multi-use cleaning products (for example, for mopping floors) may contain bleach, and decalcifiers and toilet cleaners may contain acids. Surfaces should be rinsed after application of a cleaning product before using a second product (if necessary).

- During and after the use of cleaning products, windows should always be opened to increase the ventilation rate. Cleaners should avoid staying in the same room immediately after the application of strongly irritant cleaning agents.

- Respiratory protection can be recommended in cases of expected high airborne exposures to ammonia or other irritants, by using a proper mask or a damp cloth.

Occup Environ Med 2005;62:581-584 doi: 10.1136/oem.2004.015032

Correspondence to: Dr J P Zock, Respiratory and Environmental Health Research Unit, Municipal Institute of Medical Research (IMIM), Dr Aiguader 80, E-08003 Barcelona, Spain; jpzock@imim.es

Competing interests: none declared

\section{REFERENCES}

1 Karjalainen A, Kurppa K, Martikainen R, et al. Work is related to a substantial portion of adultonset asthma incidence in the Finnish population. Am J Respir Crit Care Med 2001;164:565-8.

2 Medina-Ramón M, Zock JP, Kogevinas $M$, et al. Asthma symptoms in women employed in domestic cleaning: a community-based study. Thorax 2003;58:950-4.

3 Messing K. Personal and community services: indoor cleaning services. In: Encyclopaedia of occupational health and safety, 4th edition. International Labor Office, 1998:100.1-100.19.

4 De Vito G, Molteni G, Camerino D, et al. Invecchiamento e lavoro: aspetti sanitari nelle attivita di pulizia (Aging and work: health aspects 
in cleaners). La Medicina del Lavoro 2000;91:387-402.

5 Babin A. Personal and community services: domestic workers. In: Encyclopaedia of occupational health and safety, 4th edition. International Labor Office, 1998:100.1-100.19.

6 Krüger D, Louhevaara V, Nielsen J, et al. Risk assessment and preventive strategies in cleaning work. Werkstattberichte Wissenschaft + Technik, Wb 13. Hamburg, 1997

7 Wolkoff P, Schneider T, Kildeso J, et al. Risk in cleaning: chemical and physical exposure. Sci Total Environ 1998;215:135-56.

8 Karjalainen A, Martikainen R, Karjalainen J, et al. Excess incidence of asthma among Finnish cleaners employed in different industries. Eur Respir J 2002; 19:90-5.

9 English JSC. Current concepts of irritant contact dermatitis. Occup Environ Med 2004;61:722-6.

10 Nielsen J. The occurrence and course of skin symptoms on the hands among female cleaners. Contact Dermatitis 1996;34:284-91.

11 Flyvholm MA. Contact allergens in registered cleaning agents for industrial and household use. $\mathrm{Br} J$ Ind Med 1993;50:1043-50.

12 Hellgren J, Lillienberg L, Jarlstedt J, et al. Population-based study of non-infectious rhinitis in relation to occupational exposure, age, sex, and smoking. Am J Ind Med 2002;42:23-8.

13 Balmes JR. Occupational airways diseases from chronic low-level exposures to irritants. Clin Chest Med 2002;23:727-35.

14 Kogevinas M, Antó JM, Sunyer J, et al. A population based study on occupational asthma in Europe and other industrialised countries. Lancet 1999;353:1750-4.

15 Zock JP, Kogevinas M, Sunyer J, et al. Asthma characteristics in cleaning workers, workers in other risk jobs, and office workers. Eur Respir J 2002;20:679-85.

16 Medina-Ramón M, Zock JP, Kogevinas M, et al. Asthma, chronic bronchitis and exposure to irritant agents in occupational domestic cleaning: a nested case-control study. Occup Environ Med 2005. In press.

17 Bernstein JA, Stauder T, Bernstein DI, et al. A combined respiratory and cutaneous hypersensitivity syndrome induced by work exposure to quaternary amines. J Allergy Clin Immunol 1994;94:257-9.

18 Reilly MJ, Rosenman KD. Use of hospital discharge data for surveillance of chemicalrelated respiratory disease. Arch Environ Health 1995;50:26-30
19 Centers for Disease Control. Chlorine gas toxicity from mixture of bleach with other cleaning products, California. JAMA 1991;266:2529-34.

20 Pascuzzi TA, Storrow AB. Mass casualties from acute inhalation of chloramine gas. Mil Med 1998; 163:102-4.

21 Tanen DA, Graeme KA, Raschke R. Severe lung injury after exposure to chloramine gas from household cleaners. N Engl J Med 1999:341:848-9.

22 Gautrin D, Bernstein IL, Brooks S. Reactive airways dysfunction syndrome, or irritant-induced asthma. In: Bernstein IL, Chan-Yeung M, Malo JL, et al. Asthma in the workplace, 2nd edn. New York: Marcel Dekker, 1999:565-93.

23 Santana VS, Loomis D, Newman B, et al. Informal jobs: another occupational hazard for women's mental health? Int J Epidemiol 1997;26:1236-42.

$24 \mathrm{Ng} \mathrm{C}$, Stone E, Blanc PD. Household chemical exposures: field testing a prevention brochure. Health Values 1994; 18:24-31.

25 Barron T, Berg C, Bookman L. How to select and use safe janitorial chemicals: Project completion report. Pollution prevention incentives for states. US EPA Region IX, California, County of Santa Clara, 1999. http://www.westp2net.org/ janitorial/05 Reportpdf. 